\title{
A treatable mimicker of cholangiocarcinoma
}

\author{
Malcolm Wells MD FRCPC ${ }^{1}$, David K Driman MBChB FRCPC ${ }^{2}$, Bandar Al-Judaibi MD FRCPC ${ }^{1,3}$
}

\section{CASE PRESENTATION}

A 68-year-old female nonsmoker, nondrinker with a medical history of hypertension presented with new-onset painless jaundice and pruritus, a three-month history of $9.9 \mathrm{~kg}$ weight loss and chronic diarrhea with four to five loose bowel movements per day. Medications included vitamin D, amlodipine and eprosartan. Physical examination was normal except for jaundice and muscle wasting. Recent colonoscopy had been normal. Total and direct bilirubin levels were $6.84 \mathrm{mg} / \mathrm{dL}$ $(116.96 \mu \mathrm{mol} / \mathrm{L})$ and $9.18 \mathrm{mg} / \mathrm{dL}(156.98 \mu \mathrm{mol} / \mathrm{L})$, respectively. Other results included an international normalized ratio of 1.0 , alanine aminotransferase level $247 \mathrm{U} / \mathrm{L}$ (normal <33 U/L), aspartate aminotransferase level $139 \mathrm{U} / \mathrm{L}$ (normal <32 U/L) and alkaline phosphatase level $524 \mathrm{U} / \mathrm{L}$ (normal 35 to $104 \mathrm{U} / \mathrm{L}$ ). Viral hepatitis serologies, and antimitochondrial antibody and anti-smooth muscle antibody tests were negative. Her alpha-fetoprotein level was $2.4 \mathrm{ng} / \mathrm{mL}$ (normal $<5 \mathrm{ng} / \mathrm{mL}$ ), total immunoglobulin (Ig) $\mathrm{G}$ was $1880 \mathrm{mg} / \mathrm{dL}$ (normal $<640 \mathrm{mg} / \mathrm{dL}$ ), carbohydrate antigen $19-9$ was $856 \mathrm{U} / \mathrm{mL}$ (normal $<33 \mathrm{U} / \mathrm{mL}$ ) and $\mathrm{IgG}_{4}$ was $890 \mathrm{~g} / \mathrm{L}$ (normal $<3 \mathrm{~g} / \mathrm{L}$ ). Doppler ultrasound, magnetic resonance cholangiopancreatography and magnetic resonance imaging of the liver were suspicious for a subtly enhancing mass $(2.8 \mathrm{~cm}$ to $4.2 \mathrm{~cm}$ in diameter) in the region of the hilum and porta hepatis, obstructing both the right and left hepatic ducts. Endoscopic retrograde cholangiopancreatography identified strictures in the central portions of the right and left hepatic duct, which was concerning for cholangiocarcinoma (Figure 1). Biliary brushings were negative for malignancy.

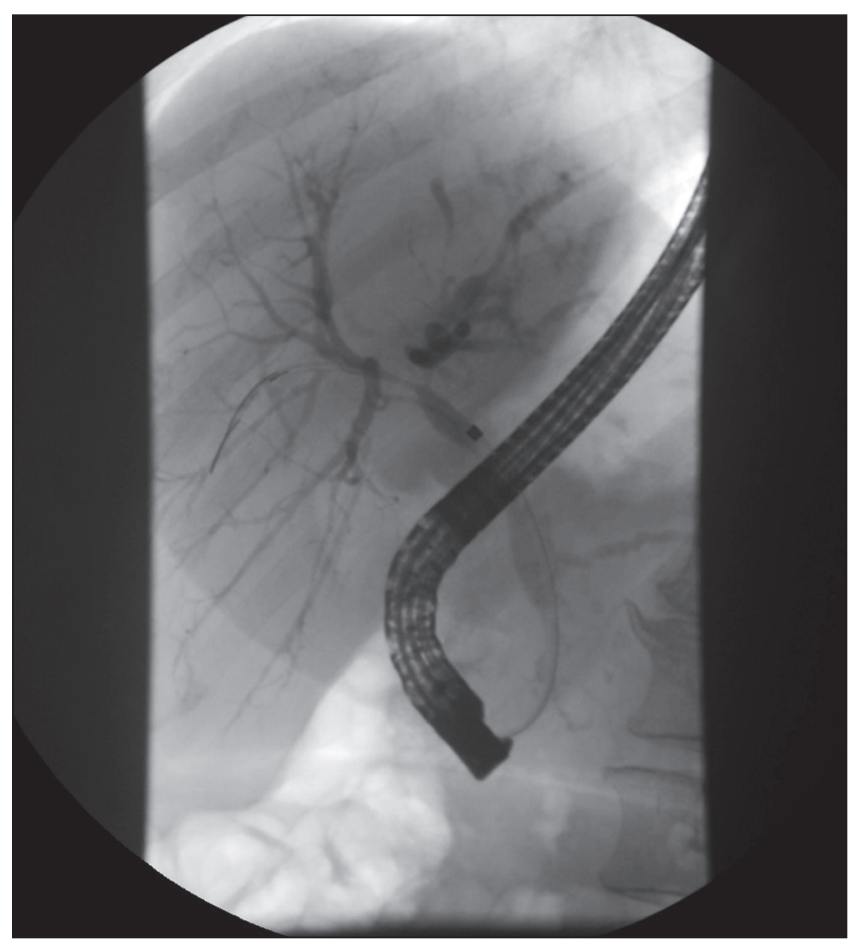

Figure 1) Endoscopic retrograde cholangiopancreatography demonstrating a filling defect in the porta hepatitis

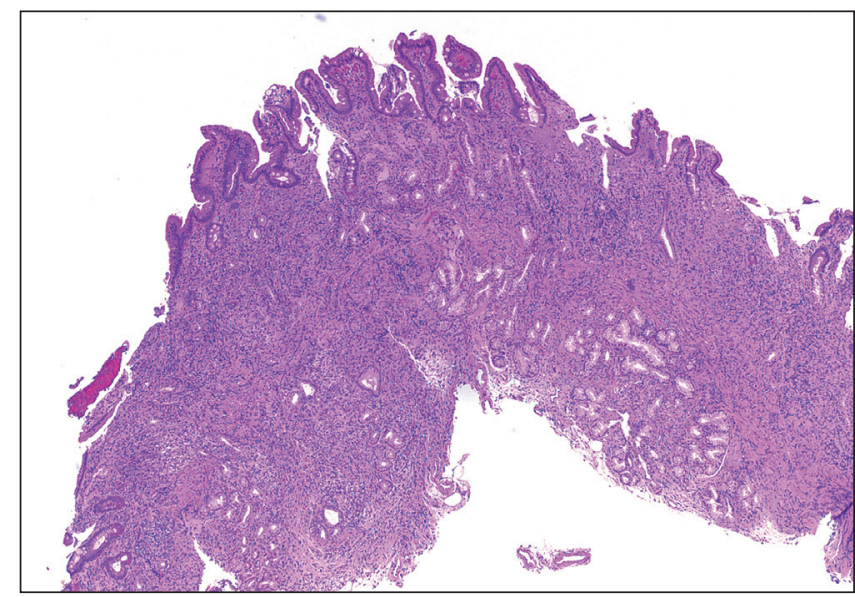

Figure 2) A biopsy of the ampulla of Vater demonstrating chronic active duodenitis. Hematoxylin and eosin stain, original magnification $\times 40$

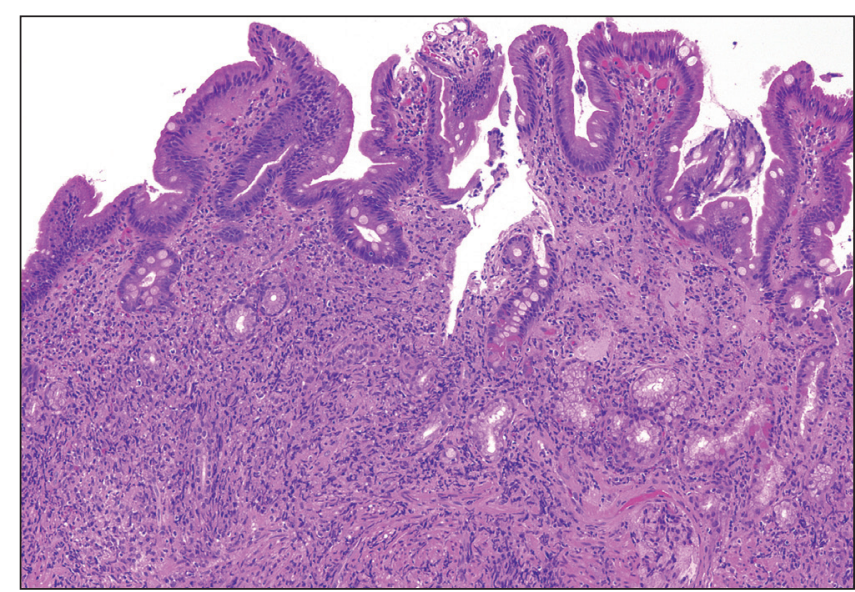

Figure 3) A biopsy of the ampulla of Vater demonstrating chronic active duodenitis. Hematoxylin and eosin stain, original magnification $\times 100$

Esophagogastroduodenoscopy was normal. Biopsies of the ampulla of Vater revealed chronic active duodenitis (Figures 2 and 3); an ancillary test confirmed the diagnosis (Figure 4). Treatment with corticosteroids normalized the patient's biochemical and radiological abnormalities within three months.

\section{DISCUSSION}

$\mathrm{IgG}_{4}$ sclerosing cholangitis ( $\mathrm{IgG}_{4} \mathrm{SC}$ ) falls within the spectrum of $\mathrm{IgG}_{4}$ related disease. Diagnostic criteria include stenosis and wall thickening of the bile duct, together with one of autoimmune pancreatitis or other $\mathrm{IgG}_{4}$ disease; or marked fibrosis and prominent infiltration of lymphocytes and $\mathrm{IgG}_{4}$-positive plasma cells in the bile duct; pancreatic cancer, cholagiocarcinoma and inflammatory bowel disease must be ruled out because $\mathrm{IgG}_{4} \mathrm{SC}$ can mimic these (1). Cholangiography is useful for discriminating $\mathrm{IgG}_{4} \mathrm{SC}$ from primary sclerosing cholangitis, but is not

\footnotetext{
${ }^{1}$ Department of Gastroenterology and Hepatology; ${ }^{2}$ Department of Pathology, Western University, London, Ontario; ${ }^{3}$ Department of Medicine, Division of Gastroenterology, King Saud University, Riyadh, Saudi Arabia

Correspondence: Dr Bandar Al-Judaibi, E2-314, University Hospital, London Health Sciences Centre, 339 Windermere, London, Ontario N6A 5 A5.

Telephone 519-685-8500, e-mail bandaraljudaibi@gmail.com

Received for publication February 3, 2015. Accepted February 8, 2015
} 


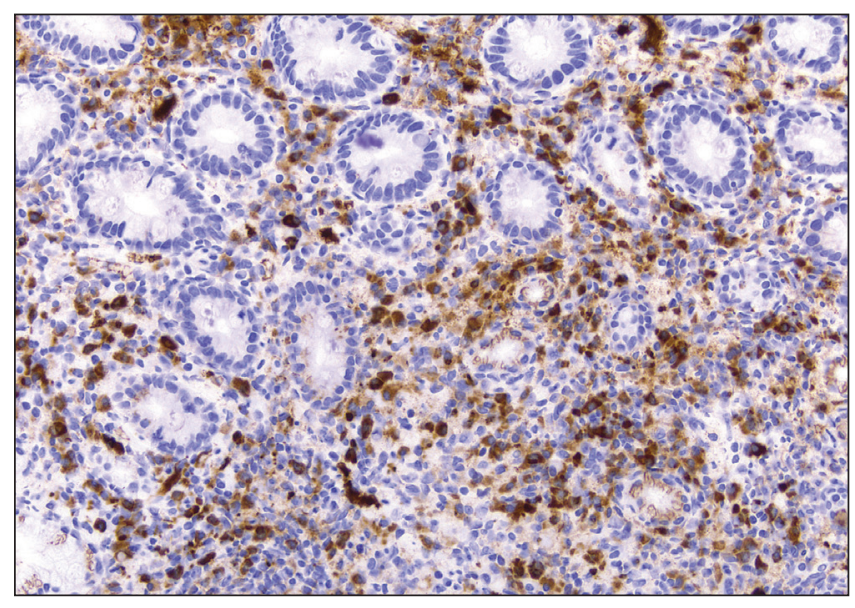

Figure 4) Positive immunoglobulin $\mathrm{G}_{4}$ staining of a biopsy of the ampulla of Vater. Original magnification $\times 200$

useful for discriminating it from cholangiocarcinoma. Therefore, the diagnosis requires an elevated serum $\mathrm{IgG}_{4}$ level and a tissue biopsy with characteristic $\mathrm{IgG}_{4}$ histopathological changes. Transpapillary intraductal ultrasonography and bile duct biopsy has high sensitivity and specificity (2), but is invasive and not widely available. Alternatively, positive $\mathrm{IgG}_{4}$ immunostaining of the major duodenal papilla, as was performed here (Figure 4 ), is specific and moderately sensitive $(3,4)$, and is less invasive than intraductal manipulation.

Treatment is based on case reports and series. Most patients respond to two to four weeks of glucocorticoid steroids. Patients who are glucocorticoid resistant or dependant may respond to azathioprine (2 $\mathrm{mg} /$ $\mathrm{kg}$ /day), mycophenolate mofetil (up to $2.5 \mathrm{~g} /$ day) or rituximab (5). Potential morbidity and mortality in untreated patients include cirrhosis and portal hypertension, retroperitoneal fibrosis, aortic aneurysms/ dissections, biliary obstruction, diabetes mellitus and lymphoma (5).
Patients with $\mathrm{IgG}_{4}$ SC progressed to liver transplantation in a significantly shorter time than patients with primary sclerosing cholangitis (1.7 years versus 6.5 years; $\mathrm{P}=0.0009$ ) (6). Therefore, $\mathrm{IgG}_{4} \mathrm{SC}$ is an under-recognized, highly treatable condition that has high morbidity if misdiagnosed as malignancy, or if undiagnosed and untreated.

\section{KEY POINTS}

- $\mathrm{IgG}_{4}$ is under-recognized by physicians due to the rarity of the disease. Increased medical awareness has an important value in making the diagnosis.

- Positive $\mathrm{IgG}_{4}$ immunostaining of the major duodenal papilla is an extremely specific and moderately sensitive tool for the diagnosis of corticosteroid-responsive $\mathrm{IgG}_{4}$-related disease

DISCLOSURES: The authors have no conflicts of interest to declare.

\section{REFERENCES}

1. Nakazawa T, Naitoh I, Hayashi K, et al. Diagnostic criteria for $\mathrm{IgG}_{4}$-related sclerosing cholangitis based on cholangiographic classification. J Gastroenterol 2012;47:79-87.

2. Nakazawa T, Naitoh I, Hayashi K. Usefulness of intraductal ultrasonography in the diagnosis of cholangiocarcinoma and $\mathrm{IgG}_{4}$-related sclerosing cholangitis. Clin Endosc 2012;45:331-6.

3. Moon SH, Kim MH, Park do $\mathrm{H}$, et al. $\mathrm{IgG}_{4}$ immunostaining of duodenal papillary biopsy specimens may be useful for supporting a diagnosis of autoimmune pancreatitis. Gastrointest Endosc 2010;71:960-6.

4. Hamano H, Kawa S, Uehara T, et al. Immunoglobulin $\mathrm{G}_{4}$-related lymphoplasmacytic sclerosing cholangitis that mimics infiltrating hilar cholangiocarcinoma: Part of a spectrum of autoimmune pancreatitis? Gastrointest Endosc 2005;62:152-7.

5. Khosroshahi A, Stone JH. Treatment approaches to $\mathrm{IgG}_{4}$-related systemic disease. Curr Opin Rheumatol 2011;23:67-71.

6. Mendes FD, Jorgensen R, Keach J, et al. Elevated serum $\operatorname{IgG}_{4}$ concentration in patients with primary sclerosing cholangitis. Am J Gastroenterol 2006;101:2070-5.

The Canadian Journal of Gastroenterology $\mathcal{E}$ Hepatology is considering a limited number of submissions for IMAGE OF THE MONTH. These
are based on endoscopic, histological, radiological and/or patient images, which must be anonymous with no identifying features visible. The
patient must consent to publication and the consent must be submitted with the manuscript. All manuscripts should be practical and relevant
to clinical practice, and not simply a case report of an esoteric condition. The text should be brief, structured as CASE PRESENTATION and
DISCUSSION, and not more than 700 words in length. A maximum of three to four images can be submitted, and the number of references
should not exceed five to seven. The submission may be edited by our editorial team. 


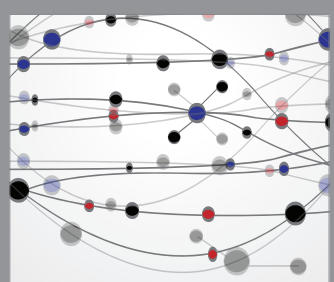

The Scientific World Journal
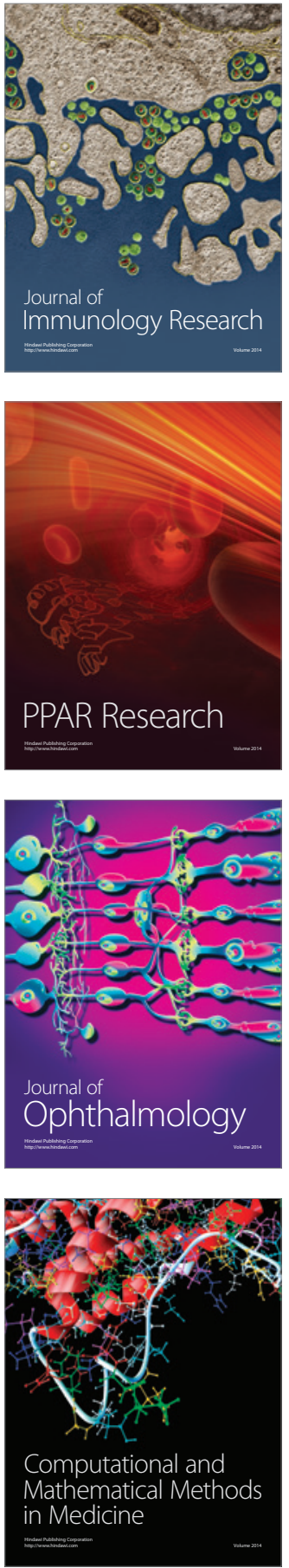

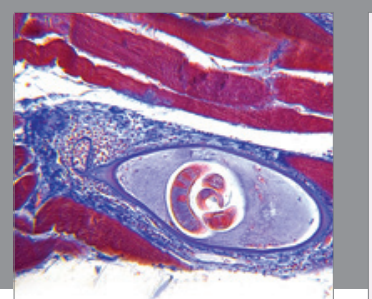

Gastroenterology Research and Practice

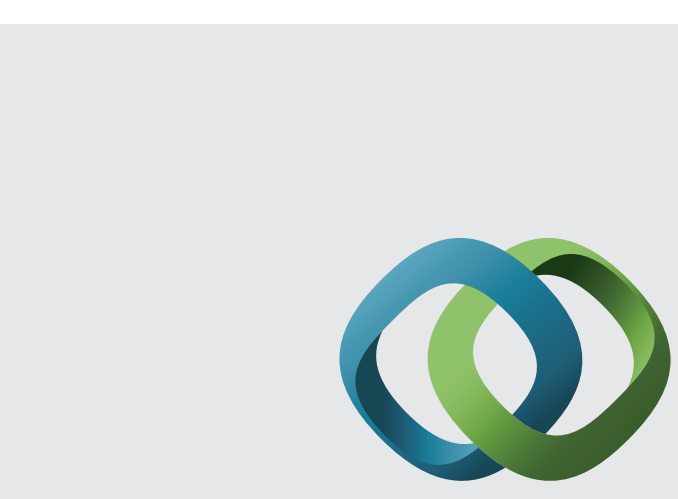

\section{Hindawi}

Submit your manuscripts at

http://www.hindawi.com
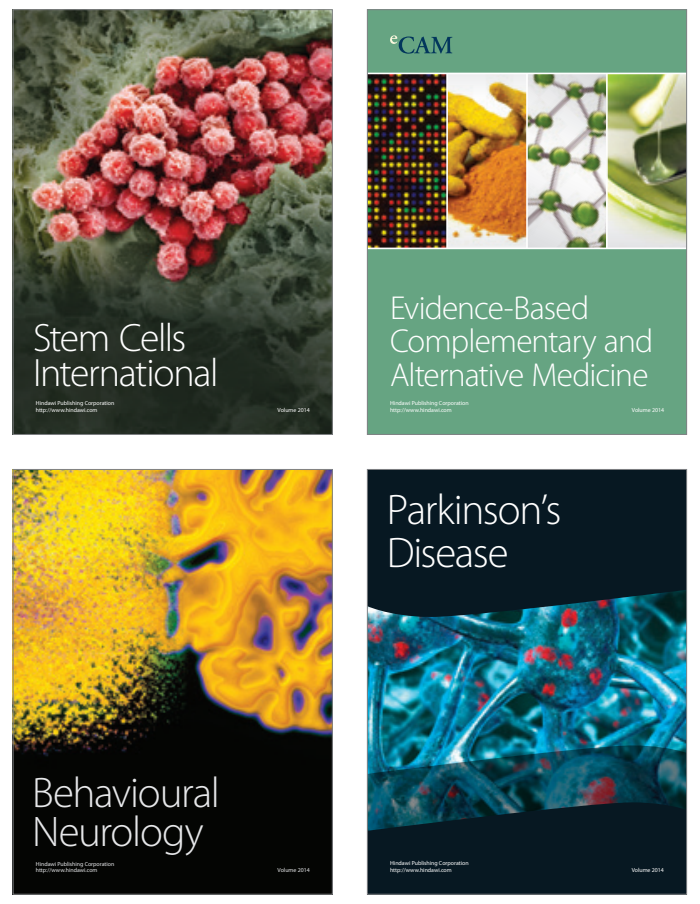
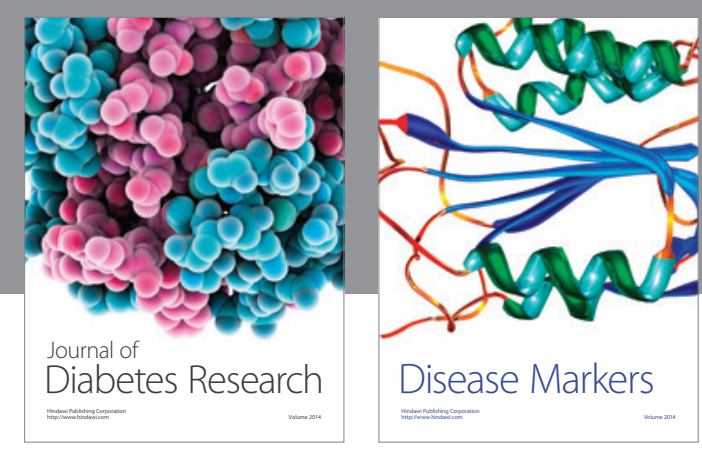

Disease Markers
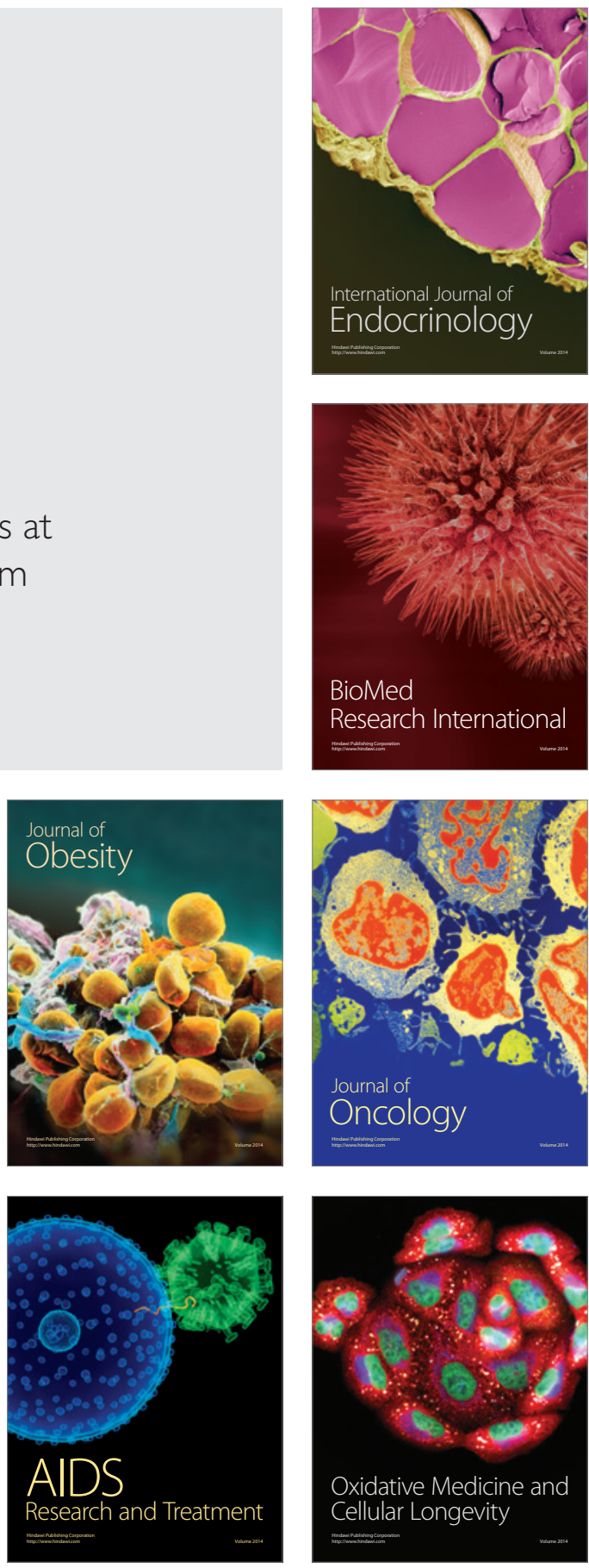